\title{
MORTE, VIOLÊNCIA E DEVASTAÇẪO EM \\ O PESO DO PÁSSARO MORTO, DE ALINE BEI'
}

\author{
DEATH, VIOLENCE AND DEVASTATION IN \\ THE WEIGHT OF THE DEAD BIRD, BY ALINE BEI
}

\author{
Jocelaine Oliveira dos Santos ${ }^{2}$
}

RESUMO: O aclamado romance inaugural de Aline Bei, $O$ peso do pássaro morto (2017), nos catapulta, abrupta e poeticamente, para a vida e as perdas de uma mulher dos seus 08 aos 52 anos. Por essa história, penso na escrita feminina (BRANCO, 2004), aportando-me na crítica feminista e de base psicanalítica, para cotejar uma provocação em torno do conceito de Devastação a partir de Lacan (1972/2008) e Marie-Helène Brousse (2004), e existência desvitalizada em Kristeva (1989), para discutir os significantes da morte, do estupro e da violência enquanto marcas constitutivas da personagem central, que tensionam o feminino por meio da destruição e ruína.

PALAVRAS-CHAVE: Violência. Crítica Feminista. Psicanálise.

ABSTRACT: Aline Bei's acclaimed inaugural novel, The Weight of the Dead Bird (2017), catapults us, abruptly and poetically, into the life and losses of a woman between 08 and 52 years old. For this story, I think of female writing (BRANCO, 2004), drawing on feminist and psychoanalytic-based criticism, to compare a provocation around the concept of Devastation from Lacan (1972/ 2008) and Marie-Helène Brousse (2004), and devitalized existence in Kristeva (1989), to discuss the signifiers of death, rape and violence as constitutive marks of the central character, which tension the feminine through destruction and ruin.

KEYWORDS: Violence. Feminist Criticism. Psychoanalysis.

\footnotetext{
${ }^{1}$ Artigo recebido em 30 de agosto de 2021 e aceito para publicação em 25 de outubro de 2021.

${ }^{2}$ Professora da área de Letras do Instituto Federal de Sergipe (IFS/ Campus Estância). Doutora em Ciências Sociais. Vice-Líder do Grupo de Pesquisa em Estudos de Texto, Leitura e Linguagem (GETELL/ IFS/CNPq). ORCID: https://orcid.org/0000-0001-8457-0382. E-mail: jocelaine.santos@ifs.edu.br.
} 


\section{Preâmbulo das escolhas (im)possíveis}

Iniciar qualquer escrita exige, não sem sofrimento, pensar sobre o exercício das escolhas aleatórias-motivadas. Paradoxalmente, é preciso explicar um pulso, um desejo, uma vontade de saber que é tão íntima quanto pública no campo acadêmico: é preciso falar do que nos move quando o que temos em profundidade é a experiência do movimento que nos trouxe até aqui.

Deste preâmbulo, intento dizer o que me agita enquanto mulher, leitora, pesquisadora e ser no mundo, cujo desejo aponta para a escuta das vozes femininas na literatura contemporânea e ao campo da psicanálise, onde me debruço sobre o feminino, a constituição das subjetividades, a prática da letra de gozo e da coisa literária, num espaço da chamada "escrita feminina".

Ao lado disso, meu lugar de mulher implicada num feminismo que vai além do identitarismo ortodoxo, pensando o lugar das mulheres (múltiplas, interseccionais, para além de qualquer artigo definido) no encontro com a subversão que pode nortear um reordenamento de discursos e práticas em uma sociedade misógina, machista, patriarcal em todas as esferas.

Atravessa-me ainda a vida real, os dados da violência de gênero, a iminência de que eu ou qualquer uma de nós, mulheres, cis ou trans, possam entrar para as estatísticas de feminicídio num país que ostenta, além do "lábaro retumbante", o 5 o lugar como o país mais letal para mulheres vitimadas pelo feminicídio (MAPA DA VIOLÊNCIA, 2015).

Deslocar-se e vincular-se frente ao tecido social. Pela literatura, pela psicanálise, pela crítica feminista contemporânea, pela realidade que nos oprime. Neste emaranhado, tento situar-me. Estas escolhas e possibilidades não deixam de apontar para ao fato de que

A experiência limítrofe que a literatura impõe a quem a encontra é a de caminhar sobre um abismo, sobre um fio de navalha, mas não são as imagens refletidas desse fio e desse abismo a experiência da literatura, pois assim estaríamos simplesmente face ao jogo de espelhos da ficção, da representação. Caminhando sobre o fio da navalha do Real, abismados, abandonados de todo e qualquer artifício, nus, pobres, nos 
daremos conta de que ainda nos resta no percurso de um corpo como súmula da sua potência de agir, um corp'a'screver (ANDRADE, 2016).

Parto, assim, desta corda bamba anavalhada que é a literatura. Chego ao aclamado romance inaugural de Aline Bei, $O$ peso do pássaro morto (2017), que me catapultou, abrupta e poeticamente, para a vida e as perdas de uma mulher sem nome, dos seus 08 aos 52 anos. Tragada por essa história, penso na escrita feminina (BRANCO, 2004), aportando-me, também, na crítica feminista (FIGUEIREDO, 2020; XAVIER, 2021) e de base psicanalítica, para cotejar uma provocação em torno do conceito de Unheimliche (o infamiliar, em Freud, 1919), de Devastação a partir de Lacan (1972/2008) e Marie-Helène Brousse (2004), e de existência desvitalizada (KRISTEVA, 1989), operados a partir do estupro e de uma vida marcada pelos traumas da personagem principal. A mim, interessa discutir os significantes da morte e da violência de gênero enquanto marcas constitutivas da personagem central, que tensionam o feminino por meio da destruição e ruína.

De uma escrita cênica, a autora nos leva a estes significantes, tecendo, sobre as perdas, um fio narrativo tenso e poético que passa pela violência sexual sofrida pela personagem ainda adolescente e pela marca de retorno deste trauma pelo filho Lucas, gerado pelo estupro, ambos atravessados pelo silêncio que imperou sobre esta mulher por toda uma vida, enodando sua impossibilidade de amar (-se).

Este romance de estreia de Bei operou em mim um atravessamento face a temas candentes no corpo social, e tidos ainda como temas-tabus como o estrupo, o corpo, a masturbação, a maternidade, o amor e seu oposto, entre outros. Na literatura, talvez herdando tantas outras mulheres que fizeram antes ${ }^{3}$, a exemplo de Clarice Lispector e Lygia Fagundes Teles (GOMES, 2014), Aline Bei também faça parte hoje de um projeto intelectual de denúncia dos valores cis-hetero-patriarcais que, por meio da violência

\footnotetext{
${ }^{3}$ Importante dizer que o projeto mulheres e escrita remonta a vários nomes fora do dito cânone, que passaram por tentativas de invizibilizações e silenciamentos plurais, sobretudo em relação às suas pautas e às consequências da estrutura patriarcal, inclusive da instituição Literatura. Partimos desse reconhecimento ao mesmo tempo em que apontamos para a escrita feminina como um construto de uma dada posição subjetiva frente à sexuação como iremos abordar no tópico 2 , fruto da guinada epistemológica incitada pelos estudos psicanalíticos e de gênero.
} 
de gênero, esboçam acentuado desprezo aos corpos femininos e ao direito à liberdade de existir.

Pelo leitmotiv "a cura não existe" que perpassa a obra, assistimos ao aniquilamento subjetivo de uma mulher que encontra a morte muito cedo, não pode esquecer a violência e silencia. Ao mesmo tempo, as estéticas da obra, do enredo e da própria escrita de Bei apontam para uma subversão dos discursos de verdade sobre a mulher suposto universal (exemplo: todas as mães devem amar seus filhos). Para além desse imaginário patriarcal, vemos um romance erguido por uma voz feminina em uma linguagem própria que se articula transpassada pelo seu modo singular de existir no mundo (NERI, 2005).

Nesse ponto, buscamos a psicanálise, como abordaremos no tópico "Escrever é mais forte", a fim de marcar uma posição sobre o que entendo quando digo "escrita feminina". É à psicanálise também que recorro para pinçar os operadores conceituais que, em alguma medida, me possibilitam traçar o mapa de retorno à obra (que sempre vem primeiro) a um gesto de leitura que ensejo fazer aqui.

No tópico seguinte, "Morrer é não mais poder escolher o que farão com sua carne", mergulho ainda mais pela bússola literária no enredo desta mulher sem nome, personagem ordinária. A mim interessa perceber a operação dos significantes morte-violência-devastação que funcionam, em meu entendimento, como amarrações para a destruição e ruína que constituem a subjetividade dessa personagem desvitalizada e aniquilada pela violência. Sem um "final feliz" pela superação ou por outra saída do trauma, vemos a personagem principal buscando um saber lidar que se esgota em si mesmo. O suicídio, enquanto abandono de si, marca essa travessia entre perdas e permanências, que pretendo discutir no tópico "Tudo escorre e Tudo é perda": devastação, existência desvitalizada e autoaniquilamento.

Enquanto posição de leitura, sempre em movimento, como as "Considerações finais", penso nas inúmeras possibilidades de alargamento operadas pelo corte de toda e qualquer crítica ao mesmo tempo em que toda cisão é sempre parcial e impossível, sobretudo diante de um texto que compõe o contemporâneo sem esgotá-lo. Desta feita, espero que minhas reflexões apontem para outras mais outras, e ainda outras leituras, num diálogo junto ao ponto de sutura Literatura-Psicanálise-Crítica Feminista. 


\title{
"Escrever é mais forte": rendando buracos (in)visíveis ou a escrita feminina no contexto da crítica literária
}

\author{
Por destino tenho que ir buscar e por \\ destino volto com as mãos vazias. \\ Mas - volto com o indizível. O indizível \\ só me poderá ser dado através do \\ fracasso da minha linguagem.
}

(Clarice Lispector)

Partindo do exercício de situar-me, chego agora a uma discussão sobre o lugar da escrita feminina neste texto, sem, sobretudo, deixar de considerar os dissensos que o termo guarda ou até sua recusa. Como o texto não trata deste desafio específico (podem surgir questões como: de fato, há lugar na crítica feminista para se pensar em "escrita feminina" sem esbarrar num possível universal perigoso?), opto por localizar o edifício explicativo em que me situo.

Em “A Mulher Escrita" (2004), as professoras Lúcia Castello Branco e Ruth Silviano Brandão tecem reflexões, no cruzamento Literatura-Psicanálise, que aqui busco retomar. Ambas discutem na obra a oposição entre a representação da mulher enquanto efeito ótico da ficção masculina e objeto alheio, espelho do outro, repetição e eco do discurso do discurso masculino ${ }^{4}$, e a subversão operada pela escrita feminina (ou a escrita mulher) a partir do horizonte da impossibilidade de se dizer tudo, cujo movimento convida a encostar a palavra à coisa-corpo por meio de outra linguagem, projeto e realização linguística que passa pela posição feminina na sexuação e na ordem do discurso (LACAN, 1972/2008).

\footnotetext{
${ }^{4}$ No início do século XX, Virginia Woolf (1882-1941) já trazia à tona a ideia da representação da muIher como objeto alheio, espelho do outro e alienação ao discurso masculino amplamente amparado no discurso hegemônico-literário da época. Mais recentemente, nos anos 80 , Glória Anzaldúa em sua "Cartas às Mulheres escritoras do 3을 mundo", aprofunda o debate e, interseccionando-o num movimento decolonial, também nos auxilia a pensar sobre direito feminino de escrever sobre si, de si e para si interditado, principalmente, às mulheres negras, latinas, chicanas, indígenas, ditas de terceiro Mundo. Anzaldúa lembra ao o leitor: "Por que sou levada a escrever? Porque a escrita me salva da complacência que me amedronta. Porque não tenho escolha. Porque devo manter vivo o espírito de minha revolta e a mim mesma também. Porque o mundo que crio na escrita compensa o que o mundo real não me dá. No escrever coloco ordem no mundo, coloco nele uma alça para poder segurá-lo. Escrevo porque a vida não aplaca meus apetites e minha fome. Escrevo para registrar o que os outros apagam quando falo, para reescrever as histórias mal escritas sobre mim, sobre você. Para me tornar mais íntima comigo mesma e consigo. (...). Finalmente, escrevo porque tenho medo de escrever, mas tenho um medo maior de não escrever." (ANZALDÚA, 1981, p. 232).
} 
Mesmo sabendo que "A escassa teoria já desenvolvida em torno de uma possível dicção feminina mais complica que esclarece." (BRANCO, 2004, p. 97), falar da escrita feminina aponta para uma escrita da posição feminina, a partir da compreensão da psicanálise, que aponta o lugar da mulher para a falta, ausência de um nome, significante vazio de uma identidade à deriva, do um a um, que se constrói para além de um gozo todo fálico, do semblante e da mascarada.

Talvez a maneira menos agressiva de abordar a questão das relações entre o feminino e a escrita seja também mais radical: aquela que envereda pelo impossível do discurso, pelos silêncios do inominável, pelos absurdos de uma pré-linguagem que se quer além (ou aquém) do verbo, mas que se quer também comunicação. Vê-se logo que, a partir do insólito e do invulgar: aqui, exatamente aqui onde se dá a singularidade, busca-se a generalização, a gramática de um discurso que se diz feminino. E aí nesse território não há como ignorar o entrecruzamento das vozes da psicanálise e da teoria literária - fala-se da morte, do esfacelamento, da fragmentação, do gozo. Afinal, é possível escrever o gozo? Do desejo, dessa falta que nos constitui e nos move não é difícil falar - aliás, fala-se sempre de uma forma ou de outra em nome do desejo. Mas, do excesso, do inútil, daquilo que sobra, daquilo que, ao contrário, não move, mas paralisa, daquilo que é perda, aniquilamento, transbordamento, voragem, como falar? (...) (BRANCO, 2004, p. 145).

Nesta esteira, o texto literário de autoria feminina, enquanto encruzilhada sêmica, aportaria provisoriamente a uma tentativa de sutura frente aos inquietantes sentidos que emergem desse encontro. É o que percebemos em operação n'O Pás$s a r O^{5}$, desde a disposição textual na página, em diálogo com as significações emergentes e impossíveis diante da perda e da dor. Há trechos que trazem a representação dos buracos e vazios que marcam o significante morte e como são reordenados (enquanto tentativa) na disposição concreta do papel. Um exemplo é o fim

${ }^{5}$ Usaremos, em referência à obra $O$ peso do pássaro morto, O peso, O Pássaro, a fim de garantir a coesão e a não-repetição do nome completo do livro. 
do capítulo Aos oito anos, página 45 da obra, em que a infância e a angústia da personagem principal pela perda de Seu Luís, após a também morte da amiga Carla, são engendradas ao espaço vazio da página quase em branco.

$\mathrm{Na}$ escrita mulher, buscamos a metáfora da renda, desenho que tenta bordar o buraco, o vazio, e a partir dele constituir uma imagem. Escrever é uma forma de lidar (ou se vingar) com a falta, sobretudo quando pensamos no trauma e a fissura operada pela sua presença. Na obra, a personagem também faz essa tentativa: escreve uma carta em que pretende contar o que lhe aconteceu ao filho Lucas, quebrando o silêncio atormentador que marca sua existência. Após fazê-lo (escrever), arremessa a carta no quintal de uma casa abandonada, inabitada, casa, ironicamente, que funcionará como jazigo de si mesma posteriormente quando decide mudar-se pra lá e acaba por cometer o suicídio neste espaço.

Também é pela escrita que a personagem, aos 8 anos, tenta entender a perda da amiga Carla ao propor a redação escolar " $A$ Cura não existe", leitmotiv que retornará em sua lápide e ao longo de sua vida. Escrever para romper os silêncios cruzados implantados pelas perdas, violências e pelo estupro na juventude. Reatualização e elaboração do trauma que impulsiona a personagem central a compor a tal carta ao filho sem nunca entregá-la:

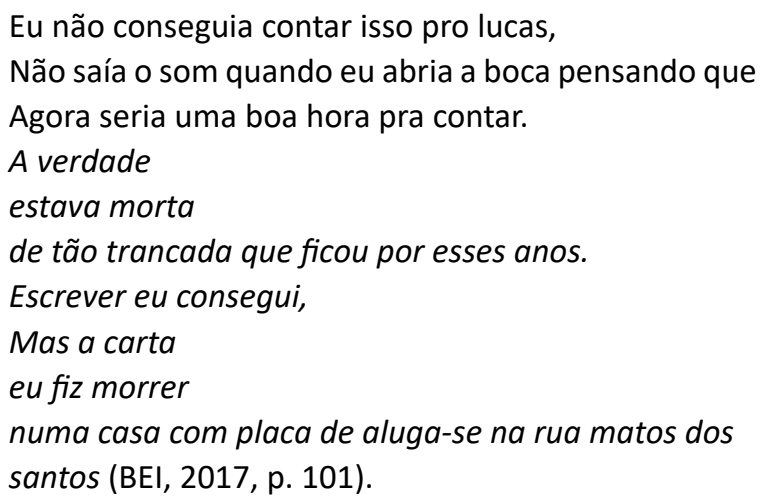

Escrita, vazio e trauma encontram-se, portanto. Pela pulsão e pela tentativa de algum parco domínio sobre o Real. A escrita feminina, assim, aponta a um desejo de conciliação impossível entre o princípio de realidade e de prazer, rasuras marcadas pelo inacessível e inabordável da alma humana, que precisa do simbólico sempre parcial. 
O que, então, de um texto que se erige a partir dessa inexistência, desse nada, e que, no entanto, insiste em sua própria materialidade, em afirmar: aqui estou eu, um texto outro, falando numa outra dicção, talvez de algo que não sei, mas que está ai, na espessa espuma do significante, na voz, no tom, na respiração, no ritmo, nas lacunas, nos excessos aqui e ali, e em nenhum lugar? Refiro-me, evidentemente a esse feminino da escrita, à escrita feminina que pretende o absurdo de dizer o indizível e que talvez por isso não diga nada além de sua incapacidade, impotência, sofreguidão (BRANCO, 2004, p. 147).

Nesse contexto, a escrita feminina emerge "para dar conta de uma falta que, a princípio, não há, as palavras servem como linhas de bordado, tricô ou crochê: todas tecendo em torno do vazio." (BARROS, 2007, p. 174), posicionada na via da Letra.

\section{"Morrer é năo mais poder escolher o que farăo com sua carne": entre permanências e perdas, morte e violência de gênero.}

Freud, ainda no início do século XX, ao tratar do que inquieta a existência humana vai nos dizer que "a frase 'todos os homens são mortais' que vem apresentada, nos manuais de lógica, como exemplo de proposição universal, para nenhuma pessoa ela é evidente, e hoje, como outrora, em nosso inconsciente não tem lugar para a ideia da mortalidade." (FREUD, 1919/2010, p. 361). Ou seja, por mais natural que sejam morrer e ver a morte, tais realidades são constantemente recompostas em nosso aparato psíquico a partir do significante do estranho familiar, do Unhemliche freudiano, aquilo que insiste em retornar como o inquietante conhecido, a partir do trauma.

N'O Pássaro, a morte concreta dos Outros e de si mesma marcarão toda a existência desta mulher sem nome. Aos 08 anos, como dissemos anteriormente, ela perderá sua amiguinha Carla e o benzedor da rua, Seu Luis, também seu amigo fiel. Depois, a morte do cachorro Vento, sua tentativa última de refazimento de si. Assim, como um traço mnêmico avassalador, a vida da personagem será permeada pela constante perda: "O problema foi a perda/da parte/ de mim que/ acreditava,/ vazou no banho um 
dia/ pelo ralo,/ escorreu e a água rápida mandou pro cano que levou/ pro rio" (BEI, 2017, p. 33).

$\mathrm{Na}$ adolescência, sua fase de experimentação e descoberta a leva para este lugar novamente, operado pelo estupro do então garoto por quem nutria desejo, Pedro. Como uma correção pelo beijo triplo dado em uma festa, Pedro estupra a personagem principal que engravida desta violência:

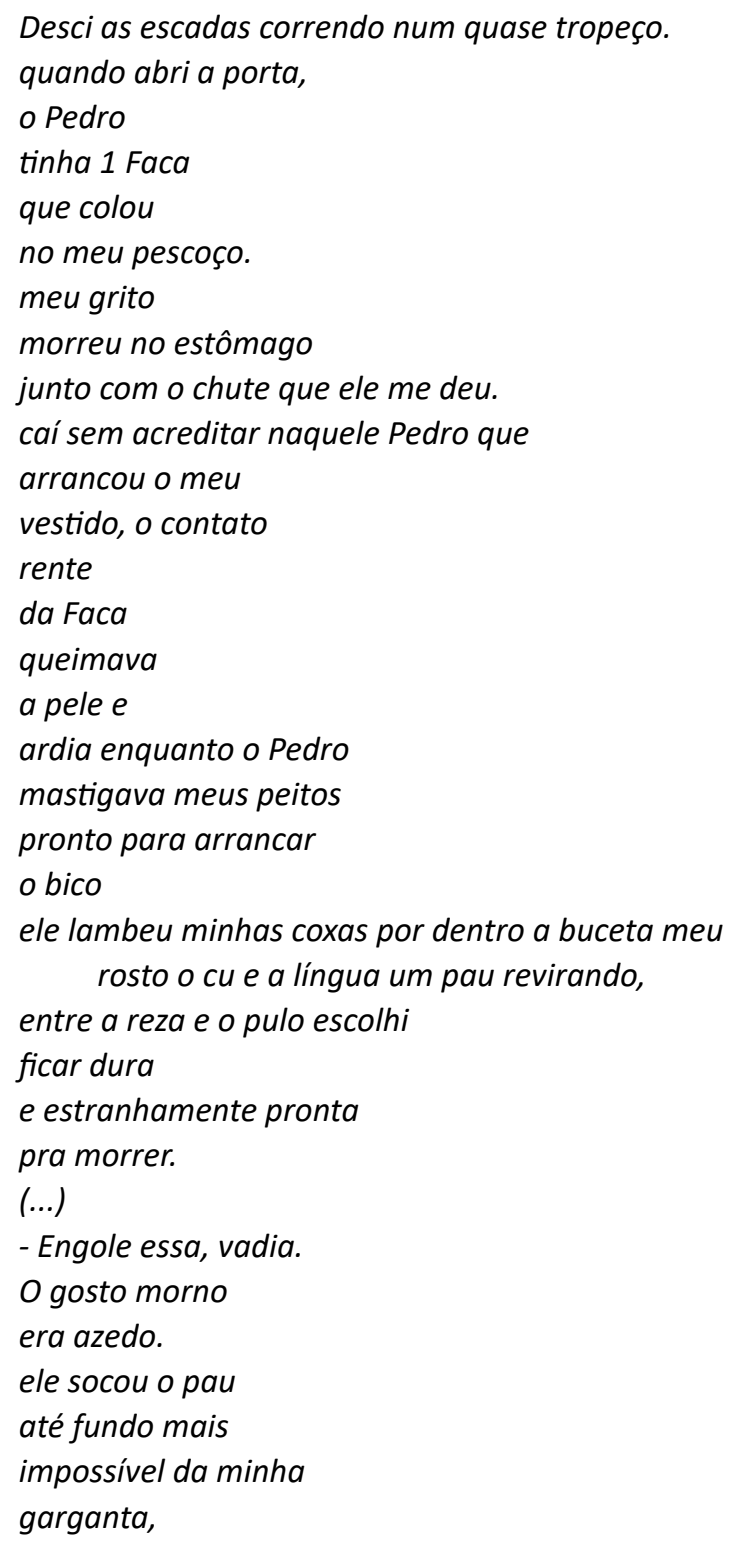




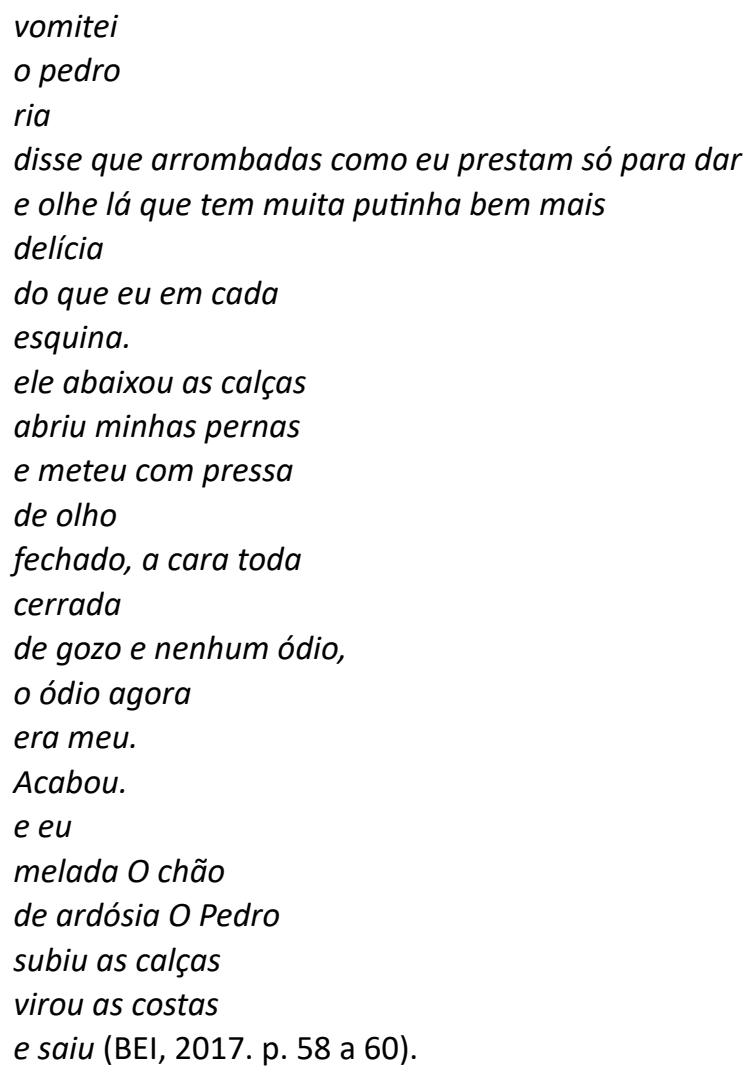

Para além da ficcionalização da realidade vivida pelas muIheres, a autoria feminina, nos lembra Figueiredo (2019), emerge enquanto (com)fabulação de um imaginário marcado sócio historicamente por uma posição no mundo, no discurso e na sexuação das mulheres. $O$ estupro ou a iminência dele fazem parte de um silêncio cruzado instaurado na sociedade que entende essa violência como naturalizada, compreensível e até mesmo autorizada. $\mathrm{Na}$ concretização da violência sexual contra a mulher, é possível apontar para estes silêncios como o promotor da repetição da inscrição traumática ao longo da vida.

Em Bei, o que vimos é a descrição euforizante, cênica, carne cortada de um estupro corretivo ao corpo desviante que não aceitou a heteronormatividade compulsória: a personagem, então aos 17 anos, havia rompido com o contrato instaurado pelo quase namoro, pelos padrões de gênero (a partir do beijo triplo com um desconhecido e uma amiga), manchando a honra de Pedro, e seu corpo deveria ser balizador desta impossibilidade de ruptura com o patriarcado. Neste contexto, 


\begin{abstract}
Consideramos o corpo feminino que é sacrificado e sofre com o suplício como um modelo disciplinador, pois tem potencial de regular as identidades femininas. Por essa perspectiva, os castigos impostos às vítimas são também formas de vigilância e estão atrelados ao controle dos padrões de gênero. (...) No campo ficcional, o corpo feminino está sendo explorado como um arquivo social que guarda a memória das regulações de gênero. (...) O suplício do corpo da mulher é um exemplo de códigos machistas mantidos por valores hegemônicos que são usados para educar pela punição, uma vez que esse corpo serve de parâmetro para que outras não sigam pelo caminho (GOMES, 2021. p. 151-153).
\end{abstract}

Corpo dilacerado sem recomposição, ele trará ainda a marca da maternidade como uma reencenação do trauma vivido - "penso que só lembrarei/ dessas duas coisas pro resto da vida,/ a minha mão na cara do lucas, / a mão do Pedro na minha cara,/ a cara do lucas/ e a cara do Pedro, acima de qualquer memória" (BEI, 2017, p. 97). No caso da obra, a maternidade é um retorno ao trauma do abuso-punitivo que ela sofreu e a experiência da impossibilidade de amar o simbólico estigmático da violência sofrida, o filho Lucas. Mais à frente, haverá a tentativa efêmera de experienciar o amor com o cachorro de nome também efêmero: Vento. Porém, o cachorro também morrerá, reafirmando o vazio e a impossibilidade de saída para a personagem, que escolhe a via do suicídio, devastada e aniquilada de si mesma.

\title{
"Tudo escorre e Tudo é perda": devastaçăo, existência desvitalizada e autoaniquilamento.
}

As pequenas e grandes tragédias que marcam a vida desta mulher ordinária acabam por tecer o emblemático e metafórico fim de sua vida. Abandona a si e em si mesma, morre engasgada em seu próprio gorfo. Escrutinando seus traumas, uma coleção: a morte de Carla e a morte de Seu Luiz, ambos que Ihes davam as respostas, levam-na à busca pela mãe que, pouco sabendo, traz o irredutível seco da morte: a mãe lhe diz - morrer é como o bife que ela fritava - sinônimo da impossibilidade de decidir o que farão com sua carne. 
Vítima de um crime sexual de estupro aos 17 anos operado como uma vingança da hegemonia masculina perdida de Pedro, defronta-se com a impossibilidade de lidar com o trauma diante da gravidez: Lucas nasce e a dor segue se inscrevendo cada dia mais, como uma ranhura cada vez mais funda no corpo.

Para a mulher que sofre recorrentes violências, o desejo passa a ser vivido como pura expressão da pulsão, o que faz com que ela seja capturada por um desamparo e uma imensa falta de recursos para conseguir mudar de posição subjetiva diante da manifestação do pior. Em cada corpo violentado, em cada palavra silenciada, o que se coloca em cena é a emergência de uma devastação subjetiva provocada por uma primeira relação na qual o que se manteve como marca primordial foi a inscrição de um gozo sem nome, um gozo que insiste em se fazer presente como atestam tragicamente as estatísticas (NAVES, 2014, p. 460).

Pela obra, aproximamo-nos da ideia de devastação em psicanálise, debatido por Lacan e Marie-Hèlene Brousse sobretudo na clínica das mulheres, a partir de um real clínico insistente ligado à compulsão à repetição, aos semblantes e sua queda, ao deslizamento dos objetos femininos, ao corpo cicatriz de um trauma e à experiência de violência, seja na relação com a mãe seja na relação com um outro, geralmente masculino.

Na primordial dialética humana, o desejo de ser o desejo do Outro e a instauração singular da linguagem do sujeito, que "toca nos confins da marcação simbólica." (BROUSSE, 2004, p. 62), podem levar a uma experiência de devastação subjetiva que tomará o sujeito em aniquilação.

Na relação de devastação - uma vez que é uma relação, e penso inclusive numa relação substitutiva à relação sexual que não há - o sujeito é despossuído do seu lugar. Esse lugar que não existe mais pode ser declinado como fala, o sujeito sendo reduzido ao silêncio; como corpo e o sujeito não passa de um 'corpo em excesso' ou uma carne desfalicizada que é um 'buraco negro'; como errância, fenômeno de despersonalização, de autoeliminação (BROUSSE, 2004, p. 65). 
O homem-devastação, seguirá explicando Brousse, reavivaria para a mulher o sem-limite do gozo e o arrebatamento diante da falta do significante mulher, com o fracasso do semblante apontando para um real fora do corpo.

N’O Pássaro, essa vida inteira marcada pelo não-encontro de amor com o filho, encaminha a personagem a sua des-vida e à "impossibilidade de uma modificação dos laços significantes" diante da tristeza e da dor (KRISTEVA, 1989, p. 16). É pelo suicídio por engasgo, metafórico e potente em sua simbolização, que esta mulher aniquilará ao trauma e a si mesma.

O que podemos perceber no texto de Bei é o caminho da personagem central ao despojamento de si mesma, operado na relação de um vazio subjetivo extremo fruto da falta de reconhecimento do outro e da violência vivida, ao mesmo tempo em que o encontro com Pedro e, posteriormente, com o filho Lucas, reavivam a agressão avassaladora que impõe o trauma como objeto persecutório da subjetividade feminina. Neste aspecto, a saída, nos dirá a psicanálise, será a invenção de um "nome próprio": a mulher deve inventar um nome pra si que lhe permita reordenar o trauma devastador deste encontro com o parceiro-agressor.

Diferentemente disso, o que vemos em $O$ Pássaro é um alastramento da tristeza, a falta de sentido, a desvitalização e perda de laços sociais significativos, operados na interioridade da personagem em meio a uma des-vida.

\section{Consideraçồes finais em movimento}

Em alguma medida, desejei pensar a obra $O$ peso do pássaro morto a partir da interface Literatura-Psicanálise-Crítica Feminista o que, por si só, exigiria um espaço de escrita e um esforço de síntese maior do que este texto apresenta. Longe de qualquer esgotamento, costurei uma análise sobre a devastação subjetiva e o desamparo esboçados pela personagem principal, retornando à imensa falta de recursos impressos a ela para contornar e mudar de posição subjetiva, caminhando para o autoaniquilamento.

O texto de Bei nos aponta para ao fato de que a violência sexual e o trauma operados incitam um movimento de despojamento de si mesmo às vítimas. Na encruzilhada deste vazio extremo subjetivo, estabelece-se, pelo desamparo e pela dor, um 
retorno persecutório da agressão, no caso da obra, insistida pela presença do trauma reatualizado na figura do filho.

Num país marcado pela insistente violência de gênero, $O$ Pássaro nos aponta temas importantes ao feminismo contemporâneo como a desromantização da maternidade, a problematização de temas como a sexualidade da mulher, o aborto, o estupro. Ao mesmo tempo, ele retoma a urgência de se romper os silêncios que constituem o trauma como uma possibilidade de, quem sabe, contornar os destinos de muitas vítimas, como o abandono de si pela devastação operada.

\footnotetext{
O trauma do estupro nunca é totalmente superado, com se vê em várias obras. (...) A mudança de paradigma na nova literatura de autoria feminina no Brasil pode ser notada na predominância de escritoras jovens, nascidas a partir de 1960 , a tematizarem o estupro (...) na atual década há uma verdadeira proliferação dessa temática, sinal de que as mulheres começaram a falar e a escrever mais sobre esses assuntos-tabu. Ainda que lidando com o imaginário, as escritoras estão inseridas na sociedade de modo que os temas candentes no momento aparecem transpostos e reelaborados numa linguagem estética (FIGUEIREDO, 2020, p. 269).
}

Nesse sentido, a escrita feminina pode apontar para um para além do que pode a página e o texto, indicando a possibilidade de bordejar aquilo que pulsa e se inscreve pelo trauma. Aquilo que nos ronda enquanto mulheres que vivem, cotidianamente, com a iminência de uma violação de seus corpos, sobretudo em um país como o nosso.

\section{Referências}

ANDRADE, V. M. B. (org). Novo dicionário de migalhas da psicanálise literária [recurso eletrônico] /- Belo Horizonte: Cas'a'screver, 2016.

BARROS, R. M. M. A escrita feminina. In RINALDI, D. COSTA, A. Escrita e Psicanálise. Rio de Janeiro: Cia de Freud, 2007.

BEI, A. O peso do pássaro morto. São Paulo: editora Nós, Edith, 2017. 
BRANCO, L. C.; B, R. S. A Mulher Escrita. Rio de Janeiro: Lamparina Editora, 2004.

BROUSSE, M. H. Uma dificuldade na análise das mulheres. In MILLER, J. Ornicar? - de Lacan a Lewis Carroll. Rio de Janeiro: Zahar, 2004.

FIGUEIREDO, E. Violência e sexualidade em romances de autoria feminina. Revista Interdisciplinar. São Cristóvão: UFS, volume 32, jul-dez, p. 137-149, 2019.

FIGUEIREDO, E. Por uma crítica feminista: leituras transversais de escritoras brasileiras. Porto Alegre: Zouk, 2020.

FREUD, S. O inquietante (1919). In FREUD, S. História de uma neurose infantil: além do princípio do prazer e outros textos (1917-1920). Obras Completas, volume 14. São Paulo: Companhia das Letras, 2010.

GOMES, C. M. O femicídio na ficção de autoria feminina brasileira. Revista Estudos Feministas. Florianópolis, UFSC, n. 22, v. 3, p. 781-794, set/dez, 2014.

GOMES, C. M. O corpo feminino como intertexto moral do feminicídio. Revista Fronteira Z: Revista do Programa de Estudos Pós-graduado em Literatura e Crítica Literária da PUC-SP, n. 26, p. 150-164, julho de 2021.

KRISTEVA, J. Sol Negro: depressão e melancolia. Tradução de Carlota Gomes. Rio de Janeiro: Rocco, 1989.

LACAN, J. Seminário 20: mais, ainda (1972). Rio de Janeiro: Zahar, 2008.

NAVES, E. T. A mulher e a violência: uma devastação subjetiva. Revista Subjetividades. Fortaleza, 14 (3): 454-462, dezembro, 2014.

NERI, R. A psicanálise e o feminino: um horizonte da modernidade. Rio de Janeiro: Civilização Brasileira, 2005.

VALLE, A. M. Beirar o impossível: a escrita de Clarice Lispector e o Real. In RINALDI, D. COSTA, A. Escrita e Psicanálise. Rio de Janeiro: Cia de Freud, 2007.

XAVIER, E. Que corpo é esse? o corpo no imaginário feminino. Rio de Janeiro: Oficina Raquel, 2021. 